\title{
Localized salt accumulation: the main reason for cotton root length decrease during advanced growth stages under drip irrigation with mulch film in a saline soil
}

\author{
WenXuan MAI, ChangYan TIAN, Li LI" \\ State Key Laboratory of Desert and Oasis Ecology, Xinjiang Institute of Ecology and Geography, Chinese Academy of Sciences, \\ Urumqi 830011, China
}

\begin{abstract}
High salinity in soil can prevent root growth of most plants. To investigate soil salinity dynamics under drip irrigation with mulch film (DI) and its effects on cotton root length, we conducted field experiments in saline soil based on a monolith method using flooding irrigation with mulch film (FI) as a control at the Korla Experimental Station of the Xinjiang Academy of Agricultural Sciences, China in 2009 and 2010. The results showed that the total root length decreased 120 days after sowing (DAS) under DI, and was mainly centered in the $0-30 \mathrm{~cm}$ soil layer and at distances of 30-70 cm from the drip-lines. There was almost complete overlap in the area of root length decline and salt accumulation. In the soil depth of $0-30 \mathrm{~cm}$ and at distances of $30-70 \mathrm{~cm}$ from the drip-lines at 110 to 160 DAS in 2009 and 171 DAS in 2010, the electrical conductivity (EC) in all soil samples was at least $3 \mathrm{mS} / \mathrm{cm}$ and in some cases exceeded $5 \mathrm{mS} / \mathrm{cm}$ under DI treatment. However, EC barely exceeded $3 \mathrm{mS} / \mathrm{cm}$ and no reduction in root length was observed under FI treatment. Correlation analysis of soil EC and root length density indicated that the root length declined when the soil EC exceeded $2.8 \mathrm{mS} / \mathrm{cm}$. The main reason for the decrease of root length in cotton under DI was localized accumulation of salinity.
\end{abstract}

Keywords: cotton; drip irrigation under mulch film; flooding irrigation under mulch film; root; salinity

Citation: WenXuan MAI, ChangYan TIAN, Li LI. 2014. Localized salt accumulation: the main reason for cotton root length decrease during advanced growth stages under drip irrigation with mulch film in a saline soil. Journal of Arid Land, 6(3): 361-370. doi: 10.1007/s40333-014-0001-0

Water shortage is a common problem in agricultural production worldwide and is one of the most important ecological factors limiting crop productivity (Bhattarai et al., 2008). Xinjiang is a typical irrigated agricultural area in arid and semi-arid regions of China (Zhang and $\mathrm{Xu}, 2011$ ). Drip irrigation with mulch film (DI) technology, as an effective water-saving measure, is widely used in Xinjiang, where it began in the late 1990s (Hu and Li, 2003). Meanwhile, as in many other arid irrigated regions, the soil in Xinjiang also shows high salinity (Tian et al., 2008). Because of the characteristic mechanisms by which salt moves with water in the soil, salt transport in a DI system is very different from that in a normal irrigation system (Zhou et al.,
2006; Malash et al., 2008), and soil salinity caused by the distribution of irrigation water often has a more significant impact on crop growth compared to other soil factors under the condition of high soil salinity (Cheeseman, 1993).

High salinity in soil inhibits the growth and development of most plants (Carmi et al., 1992, 1993). Roots are in direct contact with the soil, and thus are the first plant organ to encounter soil salinity, and potentially suffer damage from salt stress (Azaizeh and Steudle, 1991). The shape and size of the root system are affected by soil salinity (Klepper, 1991; Wei et al., 2002). Root length is more scientifically meaningful than root dry weight for evaluation of plant root

*Corresponding author: Li LI (E-mail: 1ili@ms.xjb.ac.cn)

Received 2013-05-07; revised 2013-09-25; accepted 2013-10-08

(C) Xinjiang Institute of Ecology and Geography, Chinese Academy of Sciences, Science Press and Springer-Verlag Berlin Heidelberg 2014 
function, because the uptake of water and nutrients by roots depends on the total soil area with which the roots have contact (Niu et al., 2010). Compared with root dry weight, root length better reflects the status of fine roots, which have a huge surface area but comparatively low dry weight, in the entire root system (Sivakumar et al., 1977; Kim et al., 2007). Salinity imposes the inhibition of root elongation rate by an effect on the size of the root growth zone as well as the magnitude of localized tissue elongation (Gregory and Eastham, 1996). The lengths of the elongation zones of maize (Pritchard, 1994), cotton (Zhong and Läuchli, 1993) and sorghum (Koryo, 1997) roots were shortened under saline conditions. Restriction of root length by salinity reduces the soil volume that can be contacted by the root system, and hence restricts the availability and uptake of water and essential minerals (Lazof and Bernstein, 1998). Because collection of whole root systems under field condition is difficult, there are few studies of root length, and even fewer in which a species has been grown on the same site over several seasons.

The main objective of the present study was to identify the salinity dynamics under DI in saline soil, and to determine the effects of salt transport in saline soil under DI on cotton root length based on a 2-year field experiment.

\section{Materials and methods}

\subsection{Study area}

The field experiments were carried out at the Korla Experimental Station of the Xinjiang Academy of Agricultural Sciences, China, in 2009 and 2010 cropping seasons. The study area is characterized by an arid climate, with an average annual precipitation of 56 $\mathrm{mm}$, an annual evaporation of $2,497 \mathrm{~mm}$ and annual sunshine hours of $2,878 \mathrm{~h}$. The annual accumulated temperature of $\geq 10^{\circ} \mathrm{C}$ is $4,252^{\circ} \mathrm{C}$, and the annual frost-free period is 205 days. The soil in the study area is sandy loam. Soil properties were analyzed before field experiments conducted in 2009 and 2010. The physical-chemical properties of the $0-30 \mathrm{~cm}$ soil layer in 2009 were: $\mathrm{NO}_{3}{ }^{-} \mathrm{N} 36.54 \mathrm{mg} / \mathrm{kg}, \mathrm{NH}_{4}{ }^{+}-\mathrm{N} 6.53$ $\mathrm{mg} / \mathrm{kg}$, $\mathrm{pH}\left(\mathrm{H}_{2} \mathrm{O}\right) 8.0$, soil density $1.33 \mathrm{~g} / \mathrm{cm}^{3}$, Olsen-P $2.88 \mathrm{mg} / \mathrm{kg}, \mathrm{NH}_{4} \mathrm{OAc}$-extracted $\mathrm{K} 152.5 \mathrm{mg} / \mathrm{kg}$ and organic matter $7.65 \mathrm{~g} / \mathrm{kg}$. The soil had a high salinity with an electrical conductivity (EC; water:soil 1:1) of $2.38 \mathrm{mS} / \mathrm{cm}$ in 2009 .

Many pits were dug in 2009 cropping season for root harvest and continued use of this trial field was not possible in the next year, so in 2010 we selected another area close to the location used in 2009. The basic soil physical-chemical properties were consistent with those recorded in 2009 except that the soil had a lower salinity with an EC value of $1.96 \mathrm{mS} / \mathrm{cm}$.

\subsection{Experimental design}

The experiments included two treatments consisting of DI and flooding irrigation with much film (FI) in two cropping seasons of 2009 and 2010. A randomized block design with three replicate plots was used in each treatment. Thus, there were six plots in total, and each plot had an area of $10 \mathrm{~m} \times 12 \mathrm{~m}$.

Seeds of cotton (Gossypium hirsutum L.) cv. XLZ9 and cv. XLZ21 were obtained from the Xinjiang Academy of Agricultural Sciences, China, and sown on 25 April 2009 and 2 May 2010 respectively at an identical density of $220,000 \mathrm{plants} / \mathrm{hm}^{2}$. Two rows (20 $\mathrm{cm}$ apart) were sown on either side of the irrigation drip-line, with a $50-\mathrm{cm}$ spacing between the row beside the drip-line and the drip-line, and a $10-\mathrm{cm}$ spacing between plants within a row (Fig. 1).

The rates and dates of water and fertilizer application under DI and FI were consistent with the local cotton agronomic practices. The total volume of water supplied by DI and FI was 4,000 and $6,000 \mathrm{~m}^{3} / \mathrm{hm}^{2}$, respectively.

Urea was applied at rates of 350 and $400 \mathrm{~kg} \mathrm{~N} / \mathrm{hm}^{2}$, of which $20 \%$ and $50 \%$ were applied before sowing

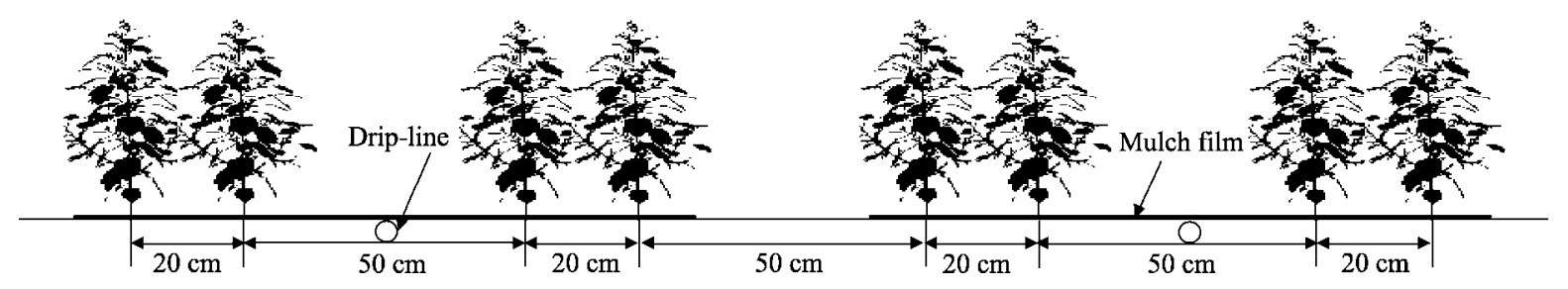

Fig. 1 Plant spacing and irrigation system used in the experiments 
as a basal dressing under DI and FI, respectively, and the remainder was applied with irrigation. In addition, $150 \mathrm{~kg} \mathrm{P} \mathrm{O}_{5} / \mathrm{hm}^{2}$ (superphosphate) and $150 \mathrm{~kg} \mathrm{~K} / \mathrm{hm}^{2}$ (potassium chloride) were applied before sowing as a basal dressing under the two irrigation treatments. The specific water and fertilizer applications in each treatment were summarized in Table 1.

\subsection{Root harvest}

A monolith method (Böhm, 1979) was used to harvest roots at seven stages (the seedling, square, first flowering, peak flowering, peak boll, late boll and maturity stages) during the growing periods at $40,65,82,96$, 110,125 and 160 days after sowing (DAS) in 2009 and at 41, 63, 81, 98, 118, 138 and 171 DAS in 2010, respectively. Soil cubes with $10-\mathrm{cm}$ sides $\left(1000 \mathrm{~cm}^{3}\right)$ were dug individually in a soil volume of $70 \mathrm{~cm} \times 20$ $\mathrm{cm} \times 60 \mathrm{~cm}$ surrounding four plants (Fig. 2). The total number of monoliths for the four plants was 84 . Each soil block was placed in a separate plastic bag and labeled with spatial coordinates. Roots in each soil block were sieved with a stainless steel mesh (1-mm diameter) and rinsed with water. Soil samples were taken from each soil block after the roots were sieved, and dried for soil EC measuring.

\subsection{Root length}

Roots collected from each soil block were scanned with a digital scanner (Epson V700, Djakarta, Indonesia) at a resolution of 200-dpi with grayscale pixels and saved as TIF image files. For scanning, the root sample in each soil block was placed in a rectangular glass dish $(200 \mathrm{~mm} \times 150 \mathrm{~mm})$ containing a water layer of $4-5 \mathrm{~mm}$ to untangle the roots and minimize root overlap. When necessary, the roots from one soil block were separated into several subsamples until they could be placed in the dish. The images were analyzed using DELTA-T SCAN version 1.0 software (Delta-T Devices, Burwell, UK).

The mean root length per plant ( $\mathrm{m} /$ plant) was calculated by dividing the total root length of the 84 soil blocks by four (the number of plants sampled).

\subsection{Soil salinity}

Soil salinity was determined by measuring EC (water:soil 1:1; Bao, 1999) using a DDS 307 conductivity meter (Leici Co., Shanghai, China). The data were presented as wireframe diagrams with Surfer 7.0 software (Golden Software, Golden, CA, USA).

Table 1 Water and $\mathrm{N}$ applications in the treatments of drip irrigation with mulch film (DI) and flooding irrigation with mulch film (FI)

\begin{tabular}{|c|c|c|c|c|c|c|c|c|c|c|c|}
\hline \multirow{2}{*}{ Treatment } & \multirow{2}{*}{$\begin{array}{c}\text { Total } \\
\text { amount }\end{array}$} & \multicolumn{10}{|c|}{ Application date and amount ${ }^{*}$} \\
\hline & & $\begin{array}{l}\text { 12 Jun } \\
14 \text { Jun }\end{array}$ & $\begin{array}{l}\text { 19 Jun } \\
\text { 22 Jun }\end{array}$ & $\begin{array}{l}\text { 26 Jun } \\
29 \text { Jun }\end{array}$ & $\begin{array}{l}3 \mathrm{Jul} \\
7 \mathrm{Jul}\end{array}$ & $\begin{array}{l}10 \mathrm{Jul} \\
12 \mathrm{Jul}\end{array}$ & $\begin{array}{l}17 \mathrm{Jul} \\
20 \mathrm{Jul}\end{array}$ & $\begin{array}{l}24 \mathrm{Jul} \\
26 \mathrm{Jul}\end{array}$ & $\begin{array}{l}1 \text { Aug } \\
5 \text { Aug }\end{array}$ & $\begin{array}{r}8 \mathrm{Aug} \\
12 \mathrm{Aug}\end{array}$ & $\begin{array}{l}16 \text { Aug } \\
21 \text { Aug }\end{array}$ \\
\hline \multicolumn{12}{|c|}{ Water $\left(\mathrm{m}^{3} / \mathrm{hm}^{2}\right)$} \\
\hline DI & 4,000 & 260 & 300 & 420 & 500 & 500 & 500 & 500 & 400 & 340 & 280 \\
\hline FI & 6,000 & & 1,200 & & & 1,800 & & 1,800 & & 1,200 & \\
\hline \multicolumn{12}{|l|}{$\mathrm{N}\left(\mathrm{kg} \mathrm{N} / \mathrm{hm}^{2}\right)$} \\
\hline DI & 280 & & 10 & 20 & 30 & 40 & 40 & 40 & 40 & 30 & 30 \\
\hline FI & 200 & & 48 & & & & & 100 & & 52 & \\
\hline
\end{tabular}

Note: ${ }^{*}$ The upper and lower dates were for 2009 and 2010, respectively. The amounts of water and fertilizer applied were identical in both cropping seasons.
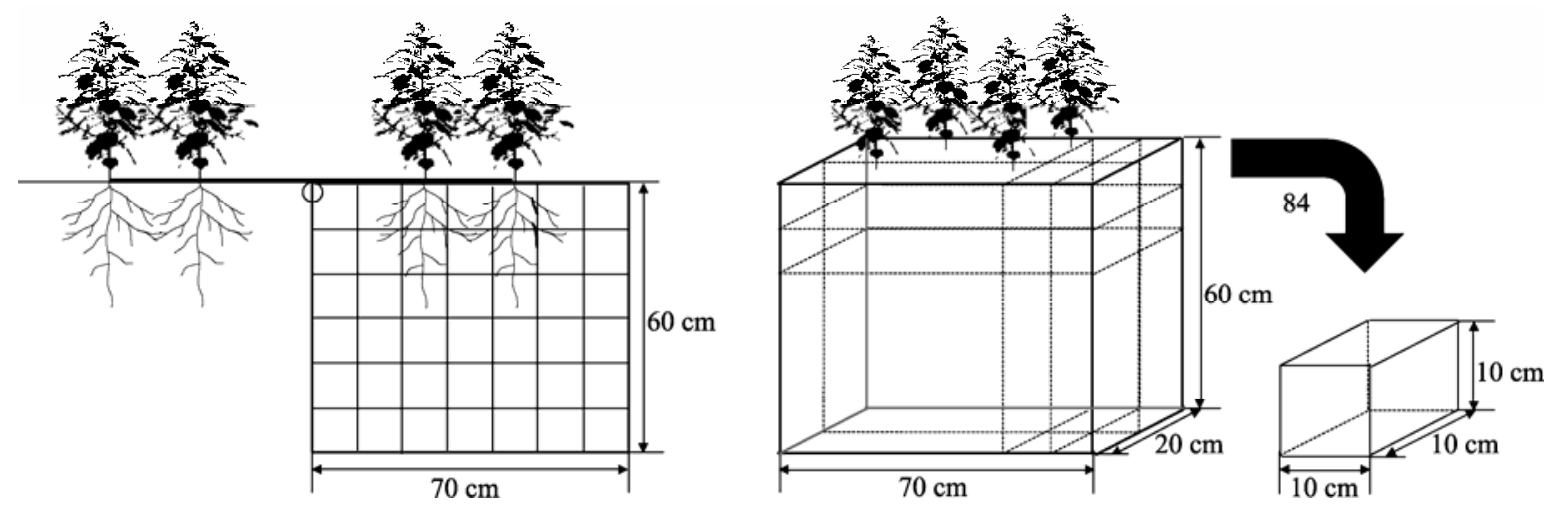

Fig. 2 Method of root collection 


\section{Results}

\subsection{Variation of root length under DI and FI}

Figure 3 shows the variation of root length per plant over different courses of the growth period under DI and FI in 2009 and 2010 cropping seasons. Root length did not show exactly the same change trends between the two cropping seasons because of the different cotton genotypes. The cotton root length under DI decreased after 120 DAS in both years, whereas under FI it was largely unchanged over the same period and even showed a slight increase trend.

The decrease in root length under DI was mainly centered in the 0-30 cm soil layer (Fig. 4), especially in the $10-20 \mathrm{~cm}$ layer $(35.96 \%$ and $37.41 \%$ decreases in 2009 and 2010, respectively), which accounted for

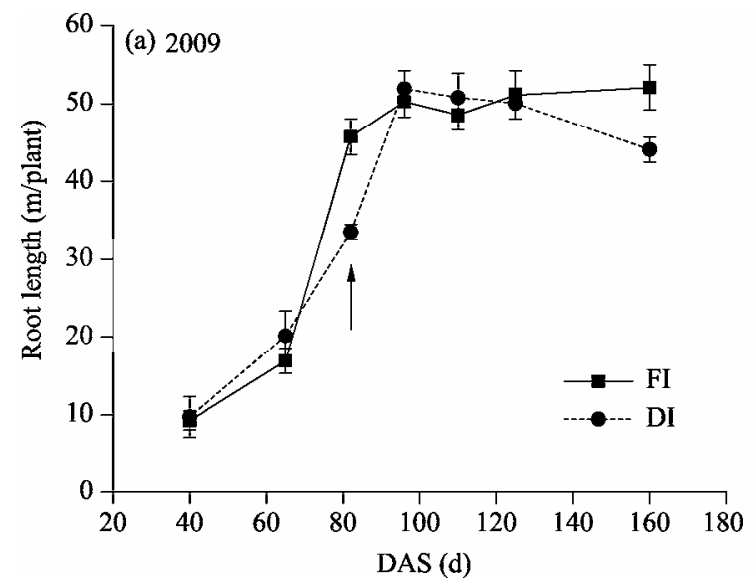

at least one-tenth of the root length per cotton plant at 110 DAS in 2009 and 118 DAS in 2010. The root length at the soil depth of $0-30 \mathrm{~cm}$ decreased horizontally at distances of 30-70 cm from the drip-lines, but the trends of this decrease presented in different extents with distances from the drip-lines, with the most obvious changes being at distances of $50-70 \mathrm{~cm}$ from the drip-lines (Fig. 5).

Figure 6 shows the distribution of root length density in the soil at different growth stages under DI and FI. The root length density in the surface soil layer $(0-10 \mathrm{~cm})$ was higher under DI than under FI, especially in 2009 cropping season. By contrast, the root length density in the lower soil layer $(40-60 \mathrm{~cm})$ was higher under FI than under DI. Similarly to the changes in root length, the root length density after

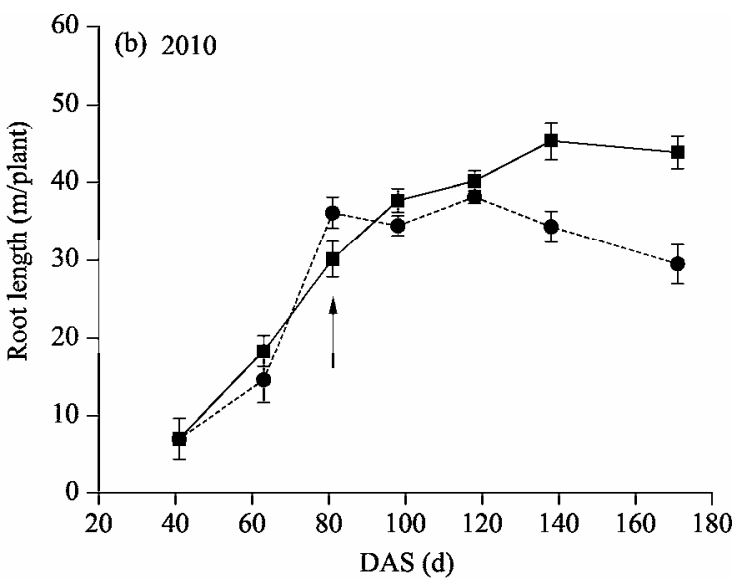

Fig. 3 Root length per cotton plant on different days after sowing (DAS) under DI (drip irrigation with mulch film) and FI (flooding irrigation with mulch film) in 2009 (a) and 2010 (b) cropping seasons. Arrows indicate the onset of flowering. Error bars represent the standard error of the mean $(n=3)$.
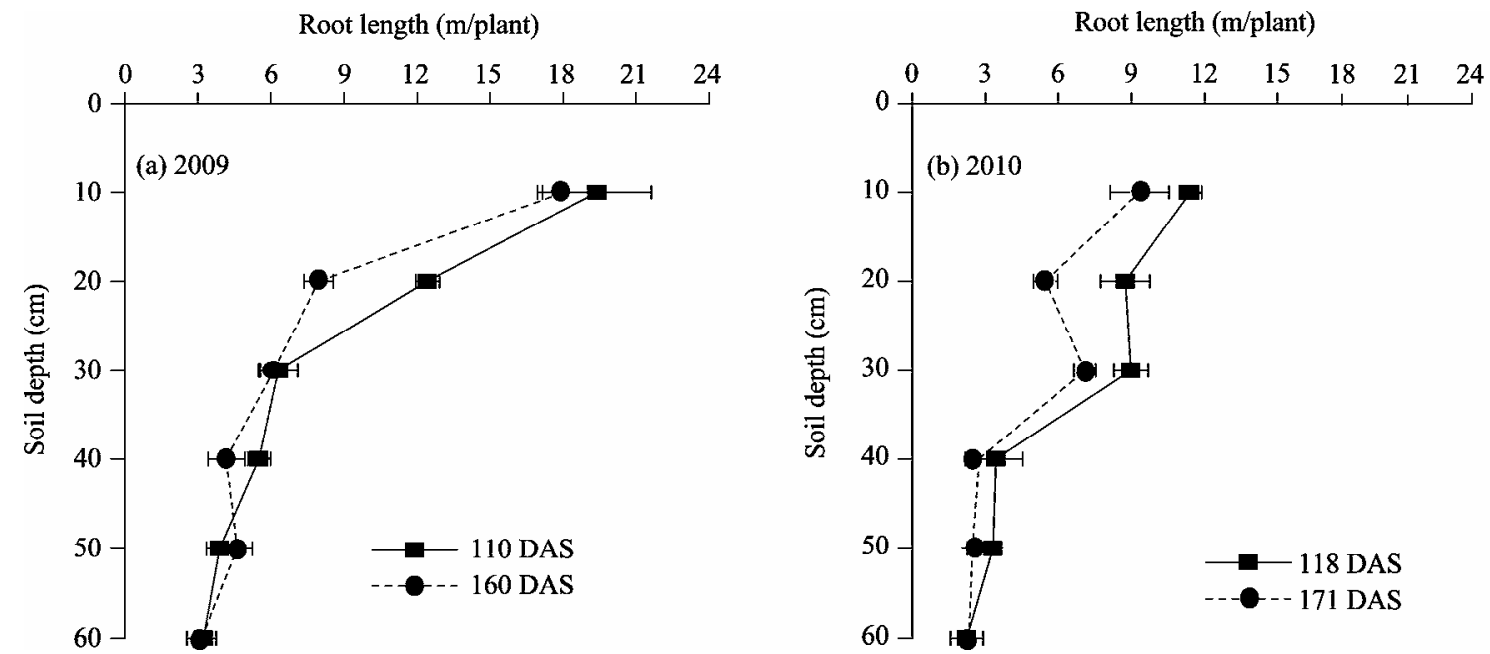

Fig. 4 Root length per cotton plant at different soil depths under DI at 110 and 160 DAS in 2009 (a), and at 118 and 171 DAS in 2010 (b). Error bars represent the standard error of the mean $(n=3)$. 

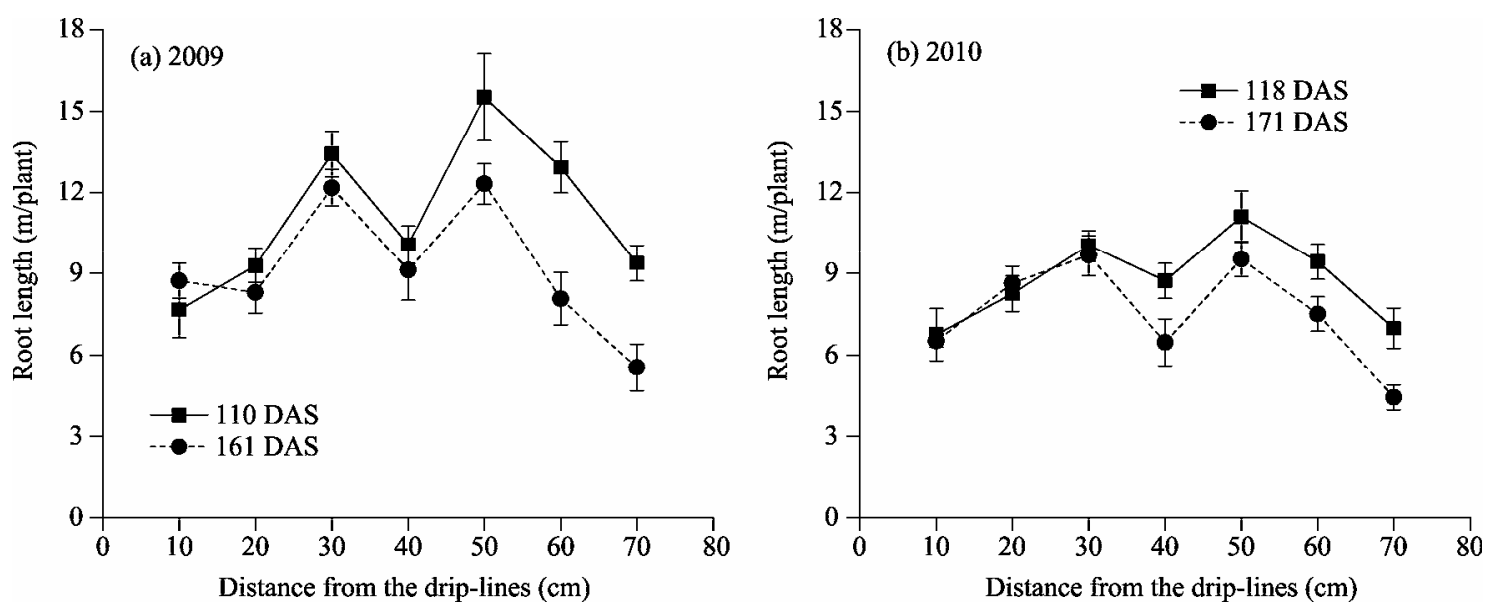

Fig. 5 Root length per cotton plant in the soil depth of 0-30 cm in relation to distances from the drip-lines under DI at 110 and 160 DAS in 2009 (a), and at 118 and 171 DAS in 2010 (b). Error bars represent the standard error of the mean ( $n=3)$.

110 DAS in 2009 and 118 DAS in 2010 decreased in the $0-30 \mathrm{~cm}$ soil layer under DI and at distances of $30-70 \mathrm{~cm}$ from the drip-lines, namely the region between adjacent mulch films. At the same time, the root length density increased under FI in this area.

\subsection{Distribution of soil salinity}

With advancing growth of the cotton plants, the average soil salinity increased in the layer of $0-30 \mathrm{~cm}$ under both DI and FI (Fig. 7). However, the average soil salinity under DI was higher than that under FI, particularly after 100 DAS. In addition, the variation in soil salinity was significantly greater under DI (mean soil EC ranged from $1.57-3.80 \mathrm{mS} / \mathrm{cm}$ and $2.08-3.01$ $\mathrm{mS} / \mathrm{cm}$ in 2009 and 2010, respectively) than under FI (mean soil EC ranged from $1.85-3.12 \mathrm{mS} / \mathrm{cm}$ and $1.99-2.66 \mathrm{mS} / \mathrm{cm}$ in 2009 and 2010, respectively). At 110 to 160 DAS in 2009 and 171 DAS in 2010, the average soil salinity under DI exceeded $3 \mathrm{mS} / \mathrm{cm}$ in the $0-30 \mathrm{~cm}$ layer. By contrast, the average soil salinity was less than $3 \mathrm{mS} / \mathrm{cm}$ under FI over the same period.

The distribution of salts in the soil differed significantly between the two irrigation treatments (Fig. 8). For instance, in 2009 cropping season, soil salinity under DI increased with distances from the drip-lines, whereas under FI it varied within a smaller range. Additionally, the soil salinity increased to at least 3 $\mathrm{mS} / \mathrm{cm}$ in the soil depth of $0-30 \mathrm{~cm}$ between 30 and $70 \mathrm{~cm}$ away from the drip-lines at 110 to 160 DAS in 2009 and 171 DAS in 2010 under DI, and the highest soil salinity greatly exceeded $5 \mathrm{mS} / \mathrm{cm}$. By contrast, the soil salinity under FI increased slightly with advancing cotton growth, and the localized accumulation of salts in the soil was not observed. Furthermore, soil salinity under FI was more evenly distributed and the area in which the soil salinity greatly exceeded 3 $\mathrm{mS} / \mathrm{cm}$ was smaller than that under DI. The same trends were apparent in 2010 cropping season, although they were less obvious than those in 2009.

\subsection{Effect of soil salinity distribution on root length}

There was almost complete overlap in the area of root length decline and salt accumulation in the soil depth of $0-30 \mathrm{~cm}$ and at distances of $30-70 \mathrm{~cm}$ from the drip-lines under DI during advanced growth stages of the cotton crop, which indicated that the salt accumulation between adjacent mulch films was the direct cause of root length decline in this region.

Correlation analyses of soil EC and root length density in the soil depth of $0-60 \mathrm{~cm}$ indicated that a soil EC of $2.8 \mathrm{mS} / \mathrm{cm}$ was a critical value for the development of root system (Fig. 9). Below this value root length increased with increasing soil salts, whereas above this value root length was inhibited as the soil salts increased. As mentioned above, soil EC under DI increased to at least $3 \mathrm{mS} / \mathrm{cm}$ in the soil depth of $0-30$ $\mathrm{cm}$ with distances of 30-70 $\mathrm{cm}$ from the drip-lines at 110 to 160 DAS in 2009 and 171 DAS in 2010, which provided further evidence that the reduction in cotton root length under DI was the result of salt accumulation in this soil layer. 


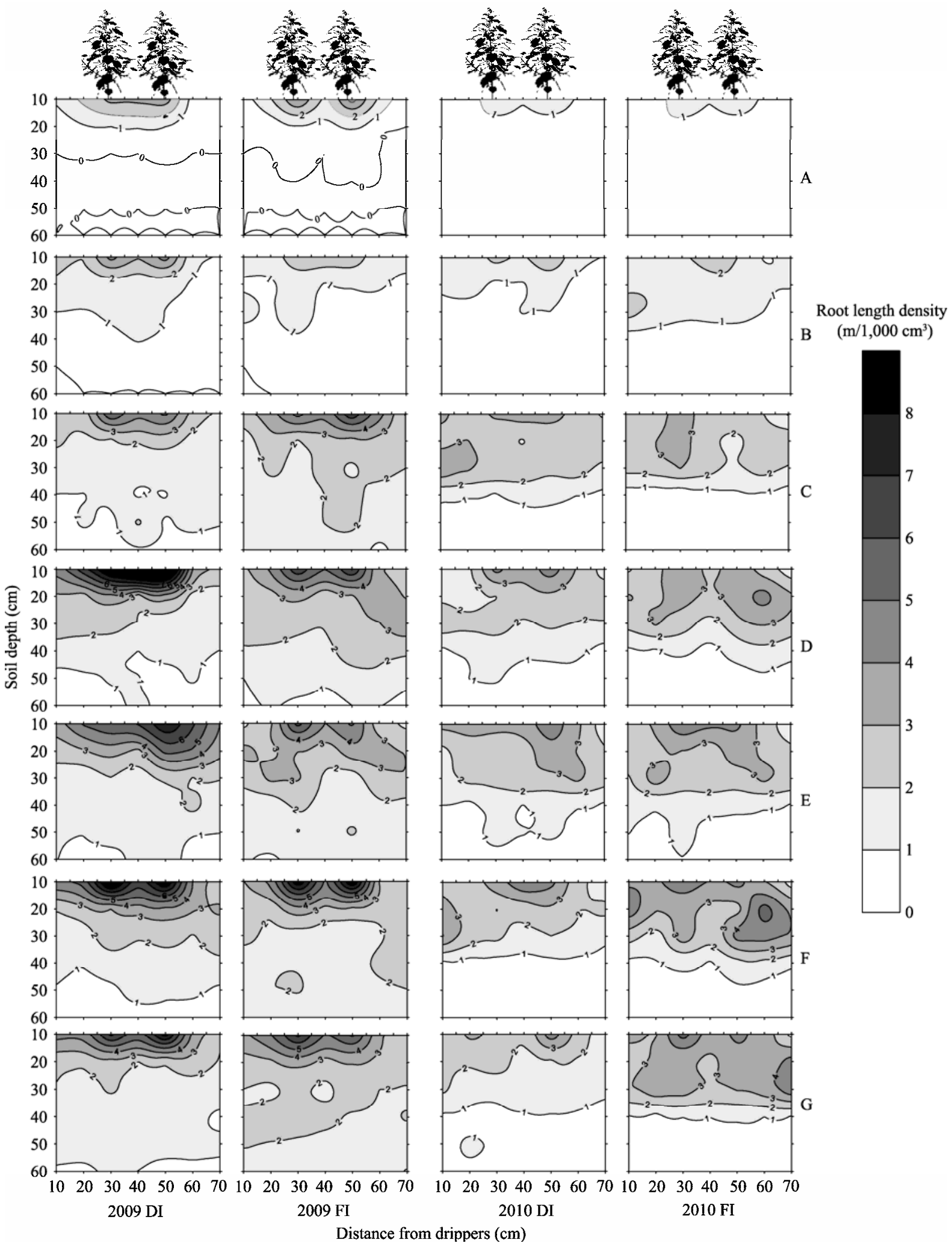

Fig. 6 Projection of root length density in the soil at different growth stages of cotton under DI and Fl in 2009 and 2010. The A, B, C, D, E, F and $G$ indicate the roots were harvested at 40,65, 82, 96, 110, 125 and 160 DAS in 2009, and at 41, 63, 81, 98, 118, 138 and 171 DAS in 2010, respectively. 

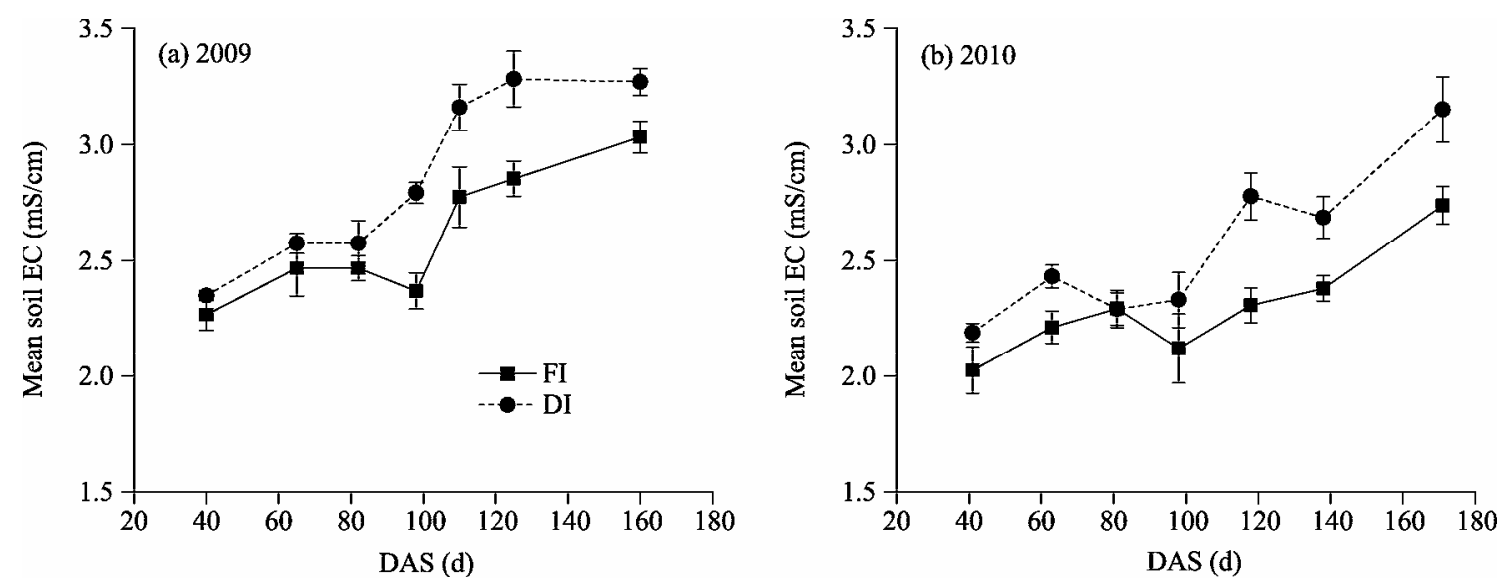

Fig. 7 Mean soil electrical conductivity (EC) in the soil depth of 0-30 cm on different DAS under FI and DI in 2009 (a) and 2010 (b) cropping seasons. Error bars represent the standard error of the mean $(n=3)$.

\section{Discussion}

In the present study, the cotton root length typically follows a sigmoidal pattern commonly observed with shoots. Based on the total root length per cotton plant, the growth period of cotton can be divided into four stages: an initial period of gradual growth, a rapid growth period, a relative stability phase, and a final decline phase. The sigmoidal pattern of growth in root length reflects the interaction between the continued formation of new roots and the death of old roots, but the relative contribution of each factor differs at different developmental stages (Li et al., 2010).

For most annuals, the shoot-to-root transport of carbohydrates will be significantly reduced when plants enter the reproductive growth stage and, subsequently, the root length often shows a rapid decline trend (Wiesler and Horst, 1993; Wang et al., 2009). Root length has not been found to increase after flowering in almost all studies with cereals (e.g. Kramer, 1980), but a substantial decrease of root length has been observed during grain-filling in some studies (e.g. Mengel and Barber, 1974). In our study, the cotton root length increased in a short period after flowering (about 20 days) under the two irrigation treatments, and then it entered a relatively stable period under FI and a decrease period under DI. The turning point of cotton root growth differed from that of other crops. For example, corn root length entered a decline phase immediately after flowering (van Nordwijk et al., 1998).

In our study, the cotton root system grew significantly faster under FI than under DI in the rapid growth period in 2009, whereas no similar results were observed in 2010. This may be due to the difference of soil salts between 2009 and 2010. Many studies have demonstrated that the environment (e.g. soil and climate conditions) can have a significant impact on plant root development (Waisel and Breckle, 1987; Neumann et al., 1994). In the present study, the difference of soil salinity in the two experimental years was an important reason that resulted in the differentia of cotton root lengths between 2009 and 2010.

The study site is a typical arid agricultural area with high soil salinity. Because of the characteristics by which salts move with water in the soil, the salt transport must be very different under different irrigation conditions. In both cropping seasons, the total cotton root length decreased significantly after 120 DAS under DI, whereas it was largely unchanged over the same period under FI. The decrease of root length under DI treatment can be attributed to the salt accumulation in the soil. Firstly, under DI treatment, the cotton root length declined significantly at the 0-30 $\mathrm{cm}$ soil depth where the salts accumulated and at distances of 30-70 cm from the drip-lines during advanced growth stages. Secondly, the root length declined when the soil EC exceeded $2.8 \mathrm{mS} / \mathrm{cm}$ in the study site. Under DI treatment, soil EC increased to at least $3 \mathrm{mS} / \mathrm{cm}$ in the soil depth of $0-30 \mathrm{~cm}$ between 30 and $70 \mathrm{~cm}$ away from the drip-lines at 110 to 160 DAS in 2009 and 171 DAS in 2010, and the highest soil EC greatly exceeded $5 \mathrm{mS} / \mathrm{cm}$. So the root length decreased significantly. The relationship between cotton root length density and soil salinity indicated that 


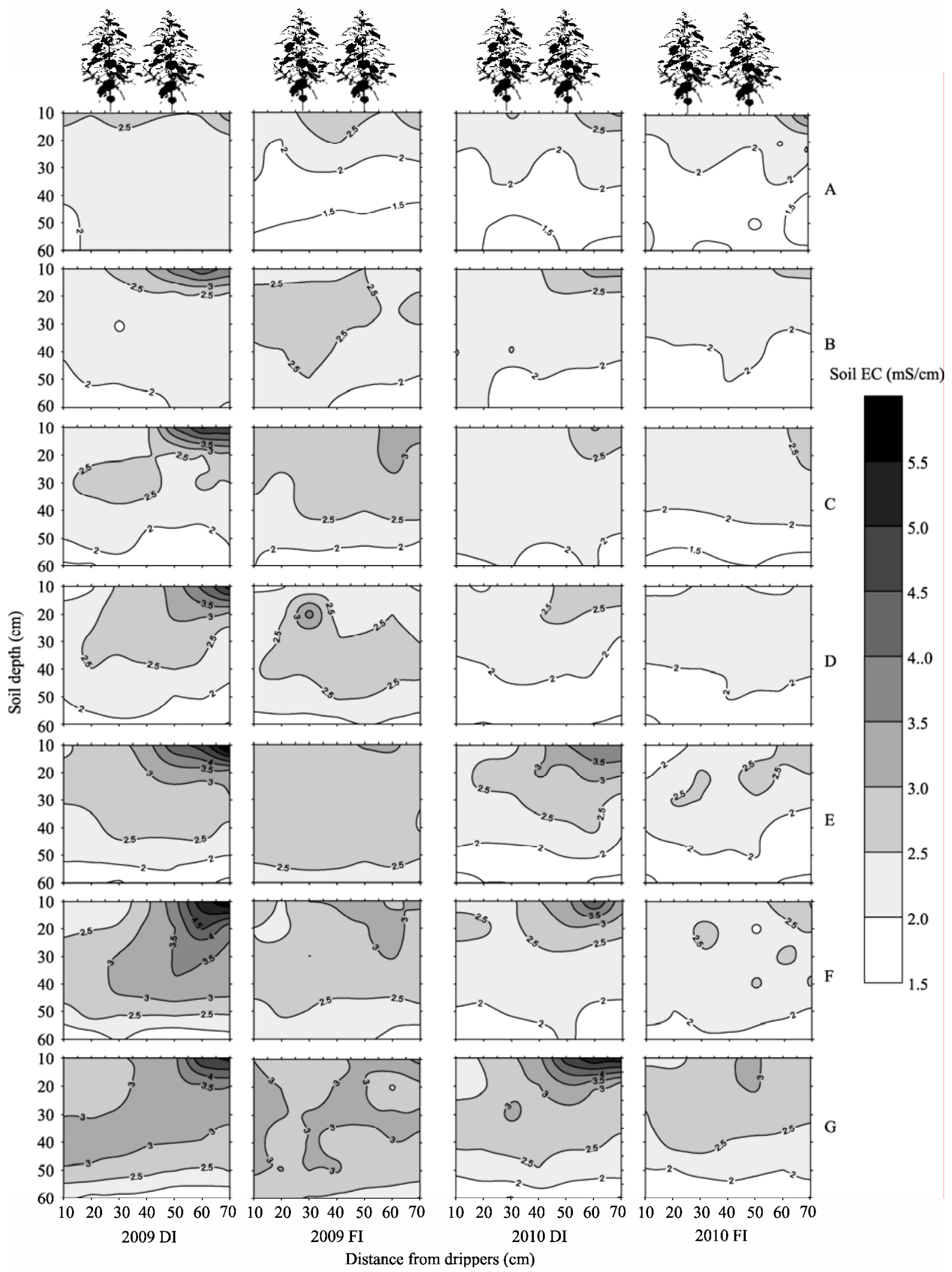

Fig. 8 Projection of EC in the soil at different growth stages of cotton under DI and FI in 2009 and 2010. The A, B, C, D, E, F and G are indicated as in Fig. 6. 

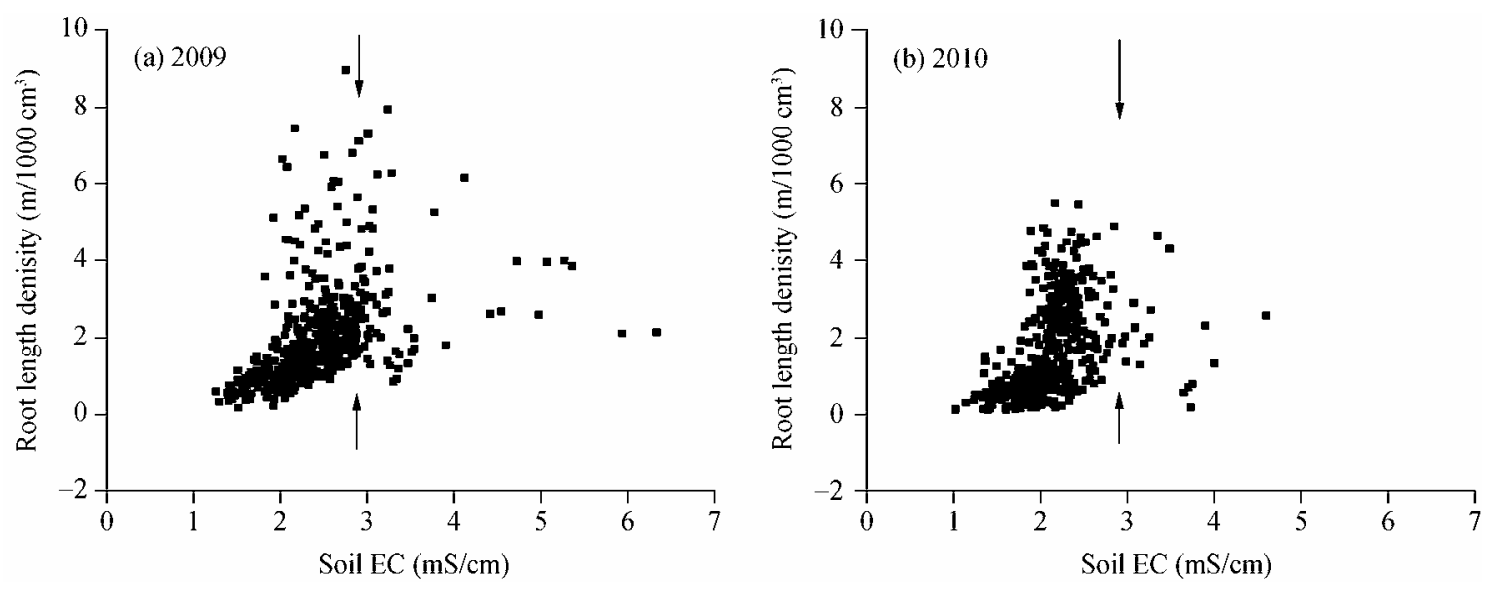

Fig. 9 Correlation between soil EC and cotton root length density in the soil depth of 0-60 cm in 2009 (a) and 2010 (b)

the root length did not show a simple decrease trend with the increase of soil salinity, and the soil salinity of $2.8 \mathrm{mS} / \mathrm{cm}$ is a critical threshold value for the development of root system. When the soil salinity exceeded $2.8 \mathrm{mS} / \mathrm{cm}$, root length decreased with increasing salt concentration, but at the salinity of less than $2.8 \mathrm{mS} / \mathrm{cm}$, root length increased with increasing salt concentration (Fig. 9). Thus, under field conditions, $2.8 \mathrm{mS} / \mathrm{cm}$ is the highest soil salinity that cotton roots can withstand. Below this value, cotton roots are able to adapt to the soil environment, but above this value, the roots will lose their capacity to develop.

Therefore, under the saline soil conditions, if the soil salinity is very high before sowing (i.e. 2009 cropping season), then the salts will strongly accumulate in the soil surface at the earlier growth stages of cotton under DI treatment, and will have a significant negative effect on the development of cotton root system; while if the soil salinity is low before sowing (i.e. 2010 cropping season), then the strong localized accumulation of salts will not be observed in the soil surface at the rapid growth period, so the negative effect of salts on cotton root system is limited. Furthermore, under DI treatment, the soil salts were strongly accumulated between the adjacent mulch films at the late developmental stages regardless of soil salt concentrations, thus the root system development is severely inhibited under salt stress. So, for avoiding the salt damage on cotton root, a large and deep root system should be developed as quickly as possible before the plants enter the reproductive growth stage.

\section{Conclusion}

Root length was strongly affected by soil salinity. Under the experimental conditions of this study, the major area in which cotton root length decreased under DI treatment coincided with the site of salt accumulation in the soil. Correlation analysis showed that the root length declined when the soil EC exceeded $2.8 \mathrm{mS} / \mathrm{cm}$. Under DI treatment soil EC could exceed $3 \mathrm{mS} / \mathrm{cm}$ in some instance and the significant decrease of root length was observed, whereas under FI treatment soil EC barely exceeded this value and no decrease in root length was found. These results indicated that under DI treatment, the localized salt accumulation was responsible for the decrease of cotton root length. The salts could accumulate quickly in the soil surface under a higher soil salinity condition, and then resulted in an adverse effect on cotton root length in the rapid growth period.

\section{Acknowledgments}

This study was funded by the National Natural Science Foundation of China (31000252, 31201681), and the Science and Technology Supporting Project of the Department of Science and Technology of Xinjiang, China (200840102-08).

\section{References}

Azaizeh H, Steudle H. 1991. Effects of salinity on water transport of excised maize (Zea mays L.) roots. Plant Physiology, 97: 1136-1145.

Bao S D. 1999. Analysis of Agricultural Chemistry in Soil. Beijing: Chinese Agricultural Press, 268-281.

Bhattarai S P, Midmore D J, Pendergast L. 2008. Yield, water-use efficiencies and root distribution of soybean, chickpea and pumpkin under different subsurface drip irrigation depths and oxygation 
treatments in vertisols. Irrigation Science, 26: 439-450.

Böhm W. 1979. Methods of Studying Root Systems. Berlin: Springer-Verlag, 156.

Carmi A, Plaut Z, Heuer B, et al. 1992. Establishment of shallow and restricted root systems in cotton and its impact on plant response to irrigation. Irrigation Science, 13: 87-91.

Carmi A, Plaut Z, Sinai M. 1993. Cotton root growth as affected by changes in soil water distribution and their impact on plant tolerance to drought. Irrigation Science, 13: 177-182.

Cheeseman J M. 1993. Plant growth modeling without integrating mechanisms. Plant Cell and Environment, 16: 137-147.

Gregory P J, Eastham J. 1996. Growth of shoots and roots, and interception of radiation by wheat and lupin crops on a shallow, duplex soil in response to time of sowing. Australian Journal of Agricultural Research, 47: 427-447.

Hu X T, Li M S. 2003. Effect of trickle irrigation under sub-film on the soil conditions of rhizosphere in cotton. Chinese Journal of Eco-Agriculture, 11(3): 121-123.

Kim H J, Lim P O, Nam H G. 2007. Senescence Processed in Plants. Oxford: Blackwell Publishing, 354-367.

Klepper B. 1991. Cotton root system responses to irrigation. Irrigation Science, 12: 105-108.

Koryo H W. 1997. Ulstrastructural and physiological changes in root cells of sorghum plants (Shorghum bicolor $\times$ S. sudanensis cv. Sweet Sioux) induced by $\mathrm{NaCl}$. Journal of Experimental Botany, 308: 693-706.

Kramer D. 1980. Plant Membrane Transport: Current Conceptual Issues. Amsterdam: Elsevier, 393-394.

Lazof D B, Bernstein B. 1989. The NaCl-induced inhibition of shoot growth: the case for disturbed nutrition with special consideration of calcium nutrition. Advances in Botanical Research, 29: 113-189.

Li C J, Peng Y F, Niu J F, et al. 2010. Real maize roots in the soil and issues should be considered by study. Plant Nutrition and Fertilizer Science, 16(1): 225-231.
Malash N M, Flowers T J, Ragab R. 2008. Effect of irrigation methods, management and salinity of irrigation water on tomato yield, soil moisture and salinity distribution. Irrigation Science, 26: 313-323.

Neumann P M, Azaizeh H, Leon D. 1994. Hardening of root cell walls: a growth inhibitory response to salinity stress. Plant Cell and Environment, 17: 303-309.

Niu J F, Peng Y F, Li C J. 2010. Difference changes in root length at the reproductive stage in maize plants grown in the field and quartz sand. Plant Nutrition and Soil Science, 173: 306-314.

Pritchard J. 1994. The control of cell expansion in roots. New Phytologist, 127: 3-26.

Sivakumar M V K, Taylor H M, Shaw R H. 1997. Top and root relations of field-grown soybeans. Agronomy Journal, 69: 470-473.

Tian C Y, Feng G, Wei C Z, et al. 2008. Integrated Management of Cotton Nutrient Resources in Xinjiang. Beijing: Science Press, 104.

van Nordwijk M, Martikainen P, Bottner P. 1984. Global change and root function. Global Change Biology, 4: 759-772.

Waisel Y, Breckle S W. 1987. Differences in responses of various radish roots to salinity. Plant and Soil, 104: 191-194.

Wang Y N, Li K X, Li X. 2009. Auxin redistribution modulates plastic development of root system architecture under salt stress in Arabidopsis thaliana. Journal of Plant Physiology, 166: 1637-1645.

Wei C Z, Ma F Y, Lei Y W, et al. 2002. Study on cotton root development and spatial distribution under film mulch and drip irrigation. Cotton Science, 14(4): 209-214.

Zhang S Q, Xu B C. 2011. Roots and Efficient Water Use of Plants. Beijing: Science Press, 237-247.

Zhong H, Läuchli A. 1993. Spatial and temporal aspects of growth in the primary root of cotton seedlings: effect of $\mathrm{NaCl}$ and $\mathrm{CaCl}_{2}$. Journal of Experimental Botany, 44: 763-771.

Zhou H P, Xu X B, Lan Y J. 1996. Review of research on soil water and salt transportation under the condition of drip irrigation under film in Xinjiang area. Water Saving Irrigation, 21(4): 8-10, 13. 